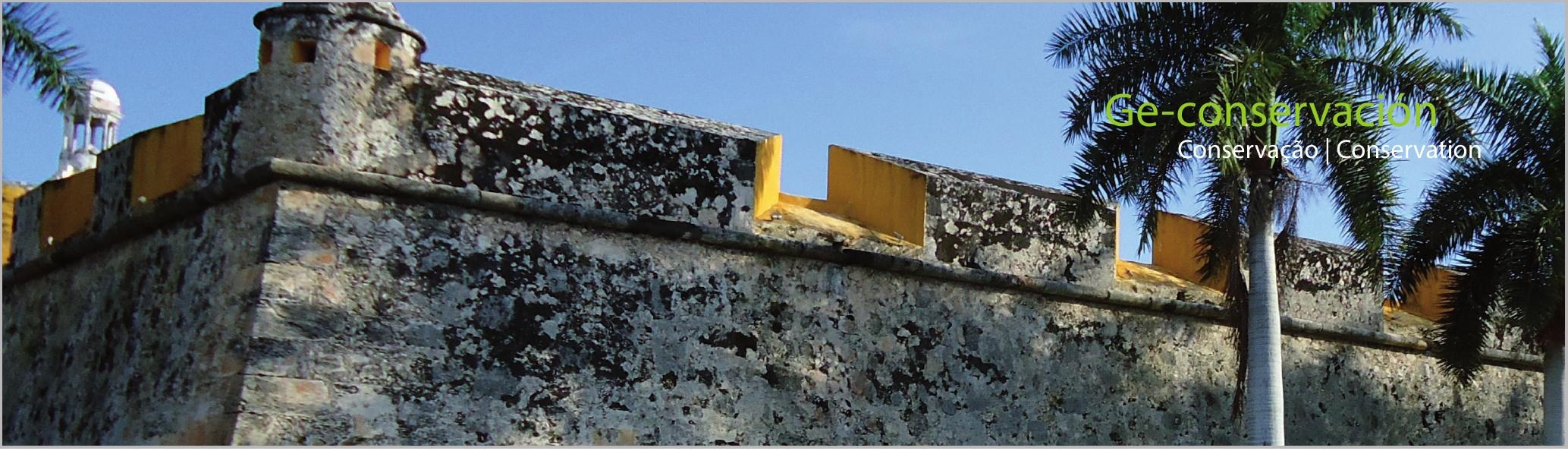

\title{
Establecimiento del grado de alteración en muros de edificios históricos de San Francisco de Campeche, México, empleando análisis de imágenes y el sistema de estadificación UAS
}

\author{
Isabel Silva León, Javier Reyes Trujeque, Claudia Escalante Díaz
}

\begin{abstract}
Resumen: La ciudad histórica de San Francisco de Campeche (SFC), México, cuenta con un importante conjunto de edificios Barrocos, construidos con mampostería de piedra caliza, expuestos al clima tropical húmedo de la región. Estos materiales sufren alteración diferencial en función de las condiciones microclimáticas específicas de su entorno. Tradicionalmente, el diagnóstico del estado de conservación de los materiales pétreos es un procedimiento que consume considerables recursos económicos y tiempo. Sin embargo, existen alternativas a estas metodologías, que también permiten determinar el alcance de posibles intervenciones en estructuras deterioradas, como la empleada en este trabajo, que combinó el análisis de imágenes, el sistema de estadificación UAS y la caracterización mineralógica mediante MEB-EDS y FTIR para establecer estadios de alteración en muros de dos baluartes del recinto amurallado de SFC.
\end{abstract}

Palabras clave: San Francisco de Campeche, edificios históricos, alteración, sistema de estadificación UAS

\section{Determination of the alteration degree in walls of historic buildings of San Francisco de Campeche, México, by using image analysis and the UAS staging system}

Abstract: The historic city of San Francisco de Campeche (SFC), Mexico, has an important set of Baroque buildings, built with limestone masonry, exposed to the humid tropical climate of the region. These materials undergo differential alteration depending on the specific microclimatic conditions of their environment. Traditionally, the diagnosis of the state of conservation of stone materials is a procedure that consumes considerable economic resources and time. However, there are alternatives to these methodologies, which also allow determining the scope of possible interventions in deteriorated structures, such as the one used in this work, which combined image analysis, the UAS staging system and mineralogical characterization using SEM-EDS and FTIR to establish alteration stages in the walls of two bastions of the SFC walled enclosure.

Keyword: San Francisco de Campeche, historic building, alteration, UAS staging system

Determinação do grau de alteração nas paredes de edifícios históricos em San Francisco de Campeche, México, usando a análise de imagens e o sistema de estadiamento UAS

Resumo: A histórica cidade de São Francisco de Campeche (SFC), no México, possui um importante conjunto de edifícios barrocos, construídos em alvenaria de calcário, expostos ao clima tropical húmido da região. Esses materiais sofrem alterações diferenciais dependendo das condições microclimáticas específicas do seu ambiente. Tradicionalmente, o diagnóstico do estado de conservação dos materiais pétreos é um procedimento que consome consideráveis recursos financeiros e tempo. No entanto, existem alternativas a essas metodologias, que também permitem determinar o alcance de possíveis intervenções em estruturas deterioradas, como a utilizada neste trabalho, que combinou a análise de imagens, o sistema de estadiamento UAS e a caracterização mineralógica tpor SEM-EDS e FTIR para estabelecer o estado de alteração das paredes de dois baluartes do recinto amuralhado do SFC.

Palavras-chave: San Francisco de Campeche, edifícios históricos, alteração, sistema de estadiamento UAS 


\section{Introducción}

Con el paso del tiempo, los edificios históricos construidos con materiales pétreos sufren alteraciones que modifican sus propiedades físicas y químicas (Gainza-Luzea 2015; IAPH 2018). Esto es más marcado en zonas urbanas, donde el crecimiento progresivo de las ciudades modifica el ambiente local, acelerando la alteración de los materiales de construcción (González y Ramírez 2015).

El material litológico de la Península de Yucatán se formó con los restos de esqueletos de animales marinos ricos en carbonato de calcio que se acumularon y posteriormente por sedimentación dieron lugar a la formación de rocas calizas. La roca caliza de la Península de Yucatán es un material rocoso suave, que puede ser fácilmente esculpido, de grano muy fino, criptocristalinas o afaníticas, en algunos casos se observan laminas o capas que sugieren intermitencia de mareas durante su formación (TorresGonzález 2009). Análisis DRX realizados en muestras pétreas de edificios históricos de San Francisco de Campeche (SFC), muestran en general composición mayoritaria de calcita $\left(\mathrm{CaCO}_{3}\right)$, con contenidos menores de aragonita (un polimorfo del $\left.\mathrm{CaCO}_{3}\right)$, silicato de sodio $\left(\mathrm{Na}_{2} \mathrm{Si}_{4} \mathrm{O}_{9}\right)$ y cuarzo $\left(\mathrm{SiO}_{2}\right)$ (Gutiérrez 2008). Respecto a sus propiedades fisicomecánicas, si bien no existen referencias a estudios en materiales locales usados en la construcción de los edificios, en rocas calizas de otros sitios de la Península de Yucatán se reportan rangos de densidad de entre 1.95 y $2.65 \mathrm{~g} / \mathrm{cm}^{3}$, resistencia mecánica a la compresión uniaxial de entre 82 y $400 \mathrm{Kg} / \mathrm{cm}^{2}$ y porcentaje de absorción de entre 2.2 y 26.84 \% (Alonzo y Espinoza 2003; Bravo et al. 2003; Torres 2008). A pesar de que este tipo de roca tiene un bajo costo de explotación y propiedades fisicomecánicas que la hacen un material de construcción por excelencia, naturalmente puede sufrir alteraciones químicas y físicas, que cambian su aspecto exterior y su comportamiento mecánico (EspinosaMorales et al. 2020; Jurado et al. 2014; Stelfox 2021). En ambientes tropicales costeros, como el predominante SFC, la alteración está influenciada principalmente por una elevada humedad ambiental, la presencia de aerosoles marinos y la proliferación de microrganismos (Escamilla et al. 2012; Jurado et al. 2014; Reyes et al. 2016).

SFC está localizada en la costa sureste del Golfo de México [figura 1]. Es un asentamiento virreinal de traza barroca con edificios que conjugan el estilo Barroco modificados en fachada durante el siglo XIX y principio del XX creando su estilo ecléctico característico, cuenta con un centro histórico fortificado de traza reticular, con alrededor de 1.500 edificios. Su procedimiento de construcción está basado en el sistema de mampostería de estilo Bahpek (típico de la Península de Yucatán), el cual consiste en el uso de piedras calizas de la región, morteros de cal y un material carbonatado blando y poco consolidado, conocido regionalmente como sahcab, que sirve de entortado para los entrepisos y azoteas (Huitz- Baqueiro 2005; Román- Kalisch 2010). El entortado se coloca entre rollizos de madera que se nivelan con una capa de sahacab, sobre la cual se añade un mortero de este último y cal, sobre esto se colocan piedras pequeñas de superficie plana, las cuales se cruzan en posición horizontal, asegurándose que la primera capa quede sobre las vigas para que carguen (Ordaz y Bojorquez 2015). Actualmente, los edificios históricos de SFC presentan diferente grado de alteración, que varía en función su ubicación y entorno microambiental.

Para un adecuado diagnóstico del estado de alteración de un edificio es necesario la identificación de indicadores de alteración y el estudio físico, químico y mineralógico de los materiales (Martín 1992). En este sentido, una adecuada inspecciónvisual permiteestimarefectos defactorescausantes de alteración e identificar patologías y los mecanismos que las originan. En muchas ocasiones, esto implica extraer fragmentos de muestras, por lo que en años recientes se ha dado preferencia al empleo métodos de evaluación no invasivos y no destructivos que minimicen daños al edificio. Por ejemplo, radiografía digital por luminiscencia, empleada para determinar la naturaleza de materiales cerámicos, estudiar su manufactura y evaluar su estado de conservación (Gómez 2016); transmisión de ultrasonido, para generar mapas de heterogeneidades en estructuras pétreas, realizar medidas indirectas de porosidad e identificar de grietas y fisuras (Bosch et al. 2005); y termografía infrarroja, que permite evaluar patrones de humedad y deterioro a partir de imágenes térmicas (Gómez- Heras 2012; Gómez- Heras et al. 2013; Gómez- Heras et al. 2014).

En este sentido, las técnicas de análisis de imágenes son herramientas de carácter no invasivo, que ayudan a establecer relaciones causa-efecto entre propiedades de los materiales y sus patologías (Prendes 2006). Su utilidad está demostrada por estudios en los cuales facilitó el establecimiento de criterios de cuantificación de daños, consecuentes con la fragilidad del material investigado de sitios tan variados como cuevas con arte rupestre, ensuciamiento de estructuras arquitectónicas y biodeterioro de materiales en zonas urbanas (Thornbush y Viles 2006; Rogerio-Candelera 2010; Rubiera 2014).

La mayoría de los esquemas descriptivos que clasifican la alteración en estructuras pétreas tradicionalmente mapean su extensión e identifican indicadores visuales de alteración (Galán et al. 1996; Arnold et al. 1998; ICOMOS 2008). Sin embargo, lo anterior requiere del entrenamiento de personal y el empleo de largos periodos de trabajo (Warke et al. 2003), por lo que es deseable el desarrollo de procedimientos alternativos, como la metodología empleada en este trabajo, conocida como Sistema de Estadificación UAS (Warke et al. 2003). El sistema UAS ofrece un procedimiento relativamente simple que se caracteriza por permitir la visualización de la dinámica de alteración presente en muros completos y cuantificar las áreas de deterioro.

La propuesta se aplicó en dos edificios de la ciudad histórica fortificada de SFC: los Baluartes de San Carlos (BSC) y San Pedro (BSP). Los resultados permitieron sistematizar una metodología para pronosticar el alcance 
de posibles intervenciones requeridas en ambos edificios intemperizados a partir de la asignación de estadios de alteración obtenidos mediante el empleo de técnicas de análisis de imágenes.

La confiabilidad de los estadios asignados se respaldó por la adición de un factor de certeza (C), obtenido mediante el análisis químico de productos de degradación retirados de los muros de ambos edificios, empleando MEB-EDS y FTIR y la identificación de sus mecanismos de deterioro predominantes. Lo anterior complementó la información obtenida y eventualmente permitirá respaldar la toma de decisiones en futuras acciones de conservación en el conjunto histórico-arquitectónico de SFC.

\section{Metodología}

\section{Área de estudio}

El centro histórico de SFC [figura 1], es un recinto amurallado de trazo hexagonal, con baluartes defensivos en sus vértices, y en su interior una amalgama de construcciones civiles, militares y religiosas erigidas entre los siglos XVI y XIX. Actualmente está rodeado por un núcleo urbano que cuenta con una flota vehicular cercana a 158.000 automóviles (INEGI 2019). Las construcciones integradas en el centro histórico presentan síntomas visibles de alteración, que reducen su valor estético y que eventualmente pueden comprometer su integridad. En SFC prevalece un tropical cálido húmedo con lluvias en verano $\left(A w_{0}\right)$, con temperatura media anual de $27,7^{\circ} \mathrm{C}$, humedad relativa promedio de $70 \%$, y precipitación anual de 1.500 mm (SMN 2020).

\section{- Baluarte de San Pedro (BSP)}

Su construcción data del año 1702. Fue la sexta fortificación del recinto amurallado de SFC. Posee una planta de tipo pentagonal, con cuatro de sus muros orientados al exterior y el oeste al interior del recinto. Se construyó en mampostería de piedra caliza, mortero de cal, arena y sahcab (un material carbonatado blando y poco consolidado). Se ubica en la esquina sureste del recinto amurallado, donde actualmente confluyen las Avenidas Circuito Baluartes y Gobernadores, en donde se ubican paraderos de autobuses del Sistema de Transporte Urbano Municipal.

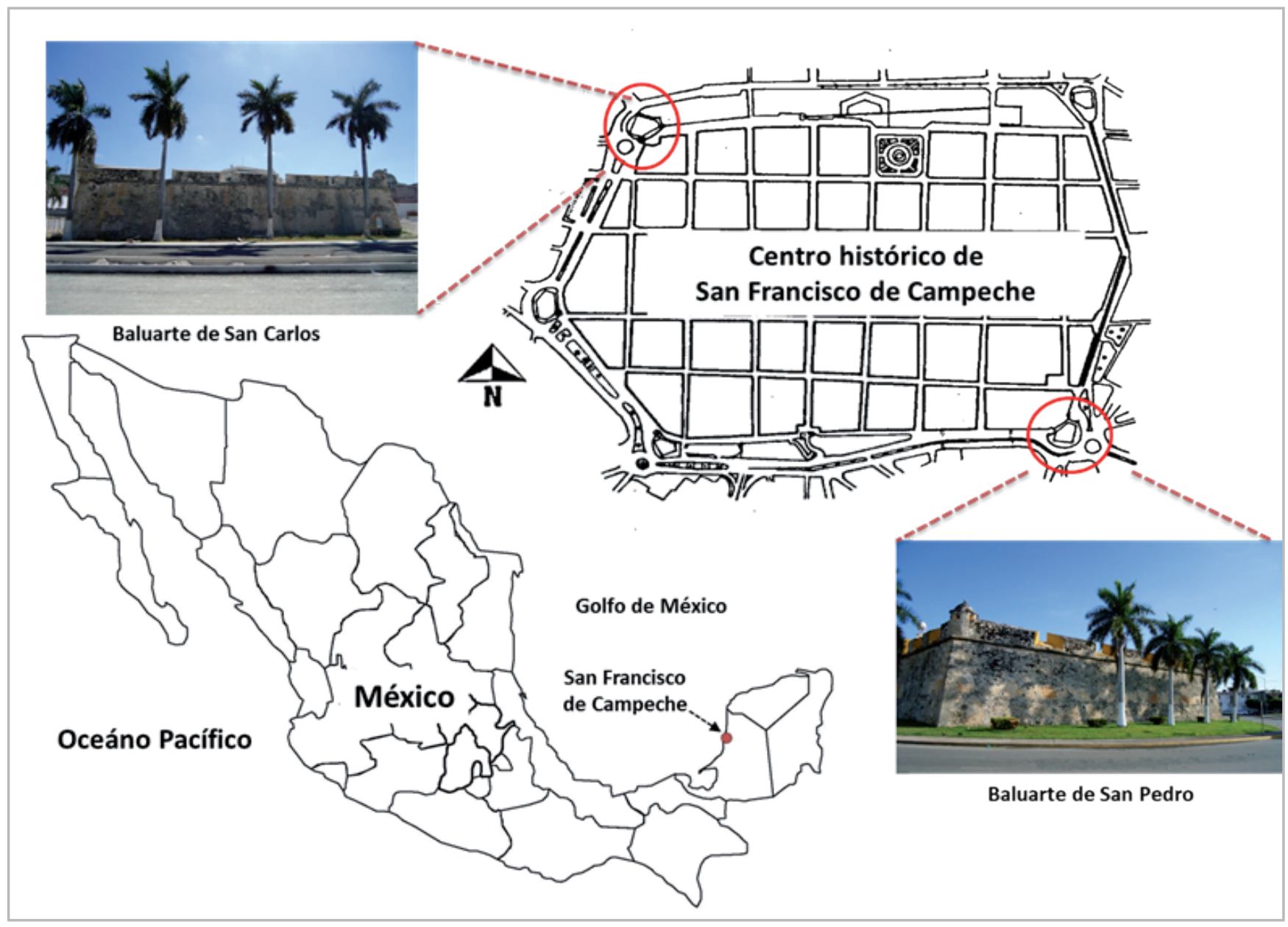

Figura 1.- Ubicación de la ciudad de San Francisco de Campeche, en el sureste de México. El Mapa del centro histórico de San Francisco de Campeche muestra la localización de los Baluartes de San Pedro y San Carlos con sus respectivas imágenes. 


\section{- Baluarte de San Carlos (BSC)}

Está localizado al noroeste del recinto amurallado [figura 1]. Se construyó en 1680, en honor al Rey Carlos II, siguiendo los mismos procedimientos constructivos usados en el BSP (Escamilla 2012; Reyes et al. 2016). Está situado entre las Calles 8 y Circuito Baluartes, a un costado del Palacio de Gobierno del Estado de Campeche.

Desde su construcción se encontraba en una zona intermareal hasta que, a mediados del siglo XX, iniciaron varios proyectos de ampliación del trazo urbano que ganaron espacio al mar, dando lugar a nuevas avenidas y modificando la condición inicial de su entorno a un tipo urbano marino.

\section{Procedimiento Experimental}

\section{— Registro fotográfico}

El registro fotográfico se realizó en enero de 2015 empleando una cámara Reflex CANNON EOS RebelT5i, montada en un trípode, con plano paralelo al suelo. Los ajustes de la cámara estaban en modo de imagen normal y condiciones de exposición y apertura del diafragma variables, ajustadas a valore ISO 100/200 dependiendo de las condiciones de iluminación. La superficie de los muros se humedeció para para mejorar el contraste entre patologías y áreas sanas.

\section{—Análisis de imágenes}

Las imágenes se escalaron y restituyeron geométricamente utilizando el paquete informático Adobe Photoshop CS5. Se hizo corrección de lente en software, realizando transformaciones en perspectiva horizontal y vertical. Posteriormente, se calcularon las áreas en pixeles cuadrados de cada indicador de alteración correspondientes a valores colorimétricos RGB similares. Los resultados se expresaron en área porcentual del muro ocupada por cada tipo de alteración.

\section{—Análisis de productos de deterioro}

Se realizó un análisis químico mediante MEB-EDS y FTIR-EDS a muestras intemperizadas retiradas de los muros de BSC $y$ $\mathrm{BSP}$, con el fin de identificar mecanismos de degradación predominantes en los materiales pétreos y fortalecer la interpretación de los estadios de alteración asignados mediante el sistema UAS. Las condiciones de los análisis se describen a continuación.

\section{- Retiro de muestras}

Se retiraron muestras representativas de los productos de deterioro presentes en ambos edificios, empleando cinceles, pinzas, martillos y espátulas finas. Se retiraron fragmentos irregulares de aproximadamente $1 \mathrm{~cm}^{2}$ [tabla 1], en total 10 muestras del BSP y 18 del BSC. Se codificaron según orientación del muro, altura y ubicación de procedencia y almacenaron en bolsas herméticas dentro de un desecador.

\section{- Espectroscopia de Infrarrojos por Transformada de Fourier acoplada a Reflectancia Total Atenuada (FTIR-ATR)}

Las muestras se pulverizaron en un mortero de ágata y analizaron en un sistema FTIR-ATR (ALPHA- BRUKER), en modo de absorbancia en el infrarrojo medio (500-4000 $\left.\mathrm{cm}^{-1}\right)$, a 24 barridos/minuto y resolución espectral de 4 $\mathrm{cm}^{-1}$. La asignación de frecuencias de vibración se realizó por comparación con la base de datos electrónica RRUFF y colecciones de espectros propias.

- Microscopía Electrónica de Barrido, acoplada a Espectroscopia de Energía Dispersiva de Rayos X (MEB-EDS)

Las muestras se analizaron sin tratamiento previo en un sistema PHILIPS ESEM XL30 acoplado a un espectrómetro de energía dispersiva de Rayos x, operando a 20 kV, distancia al haz de electrones de $10 \mathrm{~mm}$ y ángulo de inclinación de $0^{\circ}$. Los espectros EDS se registraron empleando un detector SUTW-Sapphire, con resolución de 131,32 eV.

\section{- Sistema de Estadificación UAS}

El Sistema UAS clasifica los procesos de alteración a partir de la observación e identificación de indicadores de deterioro (Warke et al. 2003). Expresa su grado de desarrollo en tres escalas espaciales: Unidad ( $U$, unit) referido a bloques individuales; Área ( $\mathrm{A}$, area) referido a bloques contiguos; $\mathrm{y}$ Propagación (S, spread) referido a fachadas completas, dichas escalas interactúan entre sí, de forma matricial, dando como resultado un estadio de deterioro. La incidencia progresiva de cada categoría refleja un incremento en las condiciones de alteración del edificio, y define el alcance de los tratamientos de conservación posteriores. A su vez, cada categoría se subdivide en los niveles 1, 2, 3 y 4 de acuerdo con la gravedad del deterioro observado [figura 2]. La fiabilidad de esta clasificación se confirmó mediante la caracterización químicoelemental y mineralógica de muestras intemperizadas. Lo anterior proporciona información sobre los mecanismos de deterioro predominantes y otorga una clasificación secundaria relacionada con la amplitud del muestreo y el procedimiento analítico empleado, para cada factor de certeza (C), apoyando a su vez la asignación de los estadios de alteración [tabla 2].

Para la clasificación, los muros se seccionaron en cuadrantes de 1,0 0,6 m simulando bloques definidos, tal como se puede observar en las imágenes adjuntas en las hojas de registro de la figura 8. Además, se propusieron nuevas especificaciones para los estadios 2 y 3, con el fin de definir mejor las características de cada estado de alteración [figura 2]. 
Tabla 1.- Relación de muestras retiradas de los muros de BSC y BSP

\begin{tabular}{|c|c|c|}
\hline Edificio & $\begin{array}{c}\text { Número de } \\
\text { muestra }\end{array}$ & Tipo de material \\
\hline \multirow{10}{*}{ BSP } & 1 & Costra/mortero \\
\hline & 2 & Costra/mortero \\
\hline & 3 & Costra/mortero \\
\hline & 4 & Costra/piedra \\
\hline & 5 & Costra/mortero \\
\hline & 6 & Costra/mortero \\
\hline & 7 & Costra/mortero \\
\hline & 8 & Costra/mortero \\
\hline & 9 & Costra/mortero \\
\hline & 10 & Costra/mortero \\
\hline \multirow{18}{*}{ BSC } & 11 & Mortero \\
\hline & 12 & Mortero/piedra \\
\hline & 13 & Mortero/piedra \\
\hline & 14 & Piedra \\
\hline & 15 & Piedra \\
\hline & 16 & Mortero/piedra \\
\hline & 17 & Mortero/piedra \\
\hline & 18 & Piedra \\
\hline & 19 & Mortero/piedra \\
\hline & 20 & Costra/mortero/piedra \\
\hline & 21 & Costra/piedra \\
\hline & 22 & Costra/mortero/piedra \\
\hline & 23 & Mortero/piedra \\
\hline & 24 & Mortero \\
\hline & 25 & Mortero sobre piedra \\
\hline & 26 & Mortero/piedra \\
\hline & 27 & Mortero \\
\hline & 28 & Mortero/piedra \\
\hline
\end{tabular}

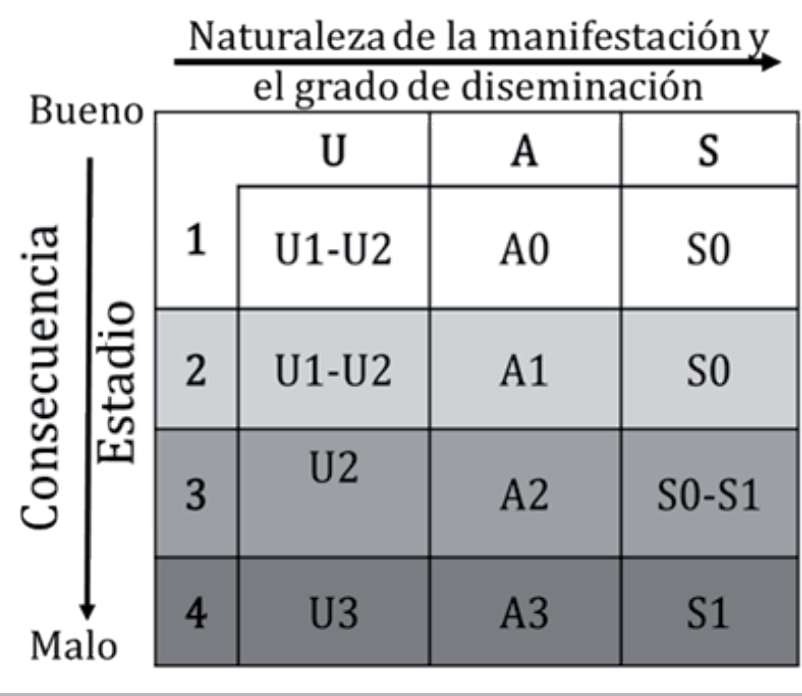

Figura 2.-Estadios de alteración ajustados del Sistema de Estadificación UAS de Warke et al. 2003

\section{Resultados y discusión}

\section{- Caracterización mineralógica}

Para establecer factores de certeza, se realizó una evaluación elemental y mineralógica empleando MEB-EDS y FTIR. La tabla 3, muestra los resultados del análisis de composición elemental mientras que la figura 3, muestra imágenes MEB representativas de las muestras.

El análisis EDS mostró como elementos mayoritarios carbono (C), oxígeno (O) y calcio (Ca), que son constituyentes de calcita $\left(\mathrm{CaCO}_{3}\right)$, el componente principal de los materiales calizos usados en la construcción de los edificios históricos de SFC. Entre los minoritarios se observó sodio (Na), magnesio (Mg),

Tabla 2.-Extensión de tratamientos de conservación en función del estadio de deterioro y factores de certeza del sistema UAS y criterios de clasificación del sistema UAS (Warke et al. 2003).

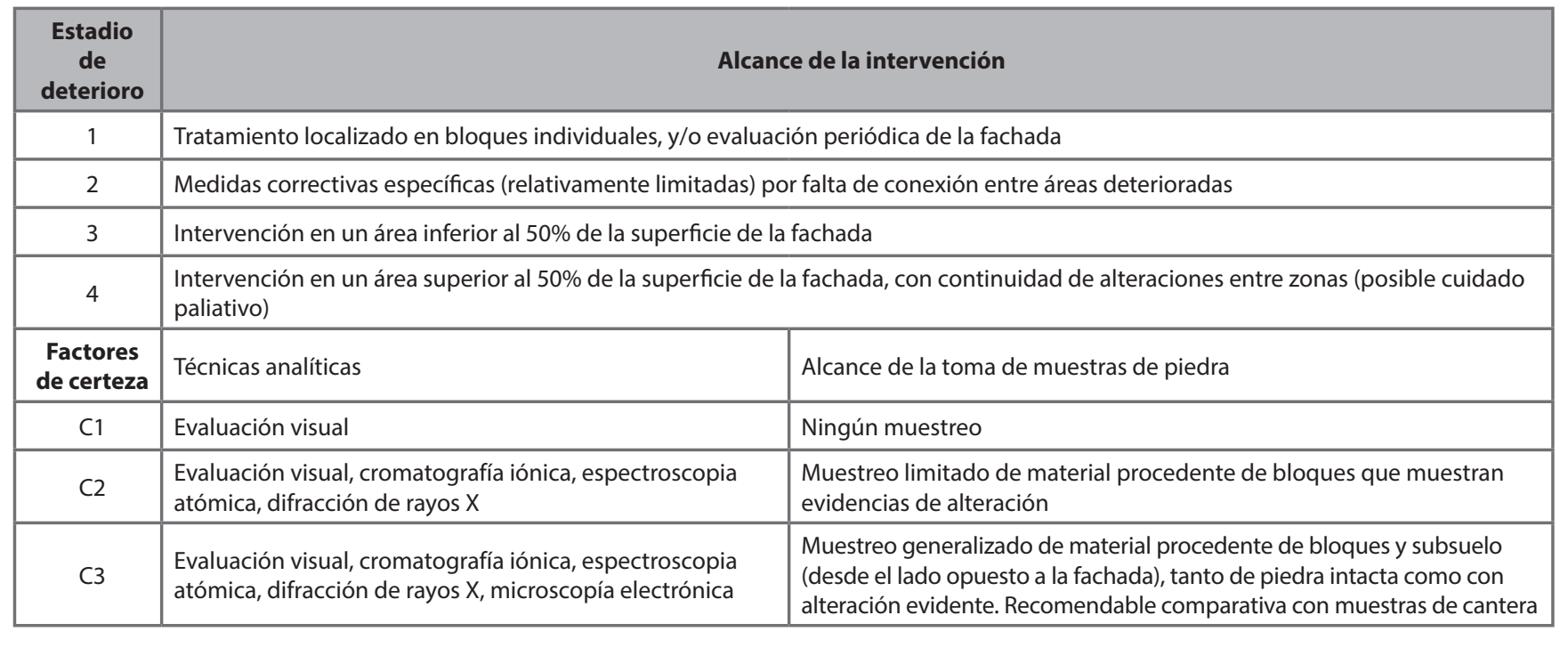




\begin{tabular}{|c|c|c|}
\hline \multirow{4}{*}{ Unidad } & U0 & Criterios de clasificación del sistema UAS \\
\cline { 2 - 3 } & U1 & No se detecta alteración en bloques individuales \\
\cline { 2 - 3 } & U2 & Alteración con mínima evidencia de ruptura que afecta áreas de bloques individuales \\
\cline { 2 - 3 } & U3 & Alteración bien desarrollada y/o ruptura obvia que afecta bloques completos \\
\hline \multirow{3}{*}{ Área } & A0 & Alteración bien desarrollada con pérdida de material menor al 10\% de la superficie de la fachada \\
\cline { 2 - 3 } & A1 & No se detecta alteración en bloques contiguos \\
\cline { 2 - 3 } & A2 & Alteración en bloques contiguos menor al $10 \%$ de la superficie de la fachada \\
\cline { 2 - 3 } & A3 & Alteración en bloques contiguos, que afecta entre 10 y $20 \%$ de la superficie de la fachada \\
\hline \multirow{3}{*}{ Propagación } & S0 & Alteración en bloques contiguos, superior al $20 \%$ de la superficie de la fachada \\
\cline { 2 - 3 } & S1 & Alteración en áreas específicas de la fachada \\
\hline
\end{tabular}

aluminio(Al), silicio(Si)y hierro(Fe), que normalmenteintegran silicatos, materiales arcillosos y arenas de sahacab de la región (Reyes et al. 2011). De igual forma se identificó, azufre (S), cloro $(\mathrm{Cl})$ y fósforo $(\mathrm{P})$, elementos ajenos a la composición mineral original de las muestras. El $\mathrm{Cl}$ es endémico de la atmósfera marina de SFC, donde se encuentra como cloruro de sodio $(\mathrm{NaCl})$, una sal higroscópica altamente móvil que se deposita y difunde al interior de la matriz pétrea, donde cristaliza, favoreciendo rupturas internas y pérdidas de material (TorresLópez 2017). Por su parte, la presencia de P probablemente está relacionada con depósitos de excrementos de aves. Estos depósitos causan afectaciones en materiales de construcción y proporcionan fuentes de carbono que favorece el anclaje y desarrollo de microorganismos y plantas superiores (Clarke y Williams 1986; Aso y Bustos 1991; Arroyo 2009: Escamilla et al. 2012). En este sentido, las muestras provenientes de zonas colonizadas mostraron enriquecimiento de $C$, consecuencia de la incorporación interna y superficial de biomasa microbiana (García-Murillo y Martín-Pérez 2006; Escamilla et al. 2012). En zonas urbanas, la presencia de $S$ se puede asociar a emisiones vehiculares. Este elemento se observó en costras negras retiradas de muros que bordean avenidas transitadas o cercanas a paraderos de autobuses (Bonazza et al. 2005; Reyes et al. 2011; Ortiz et al. 2012; Reyes et al. 2012).

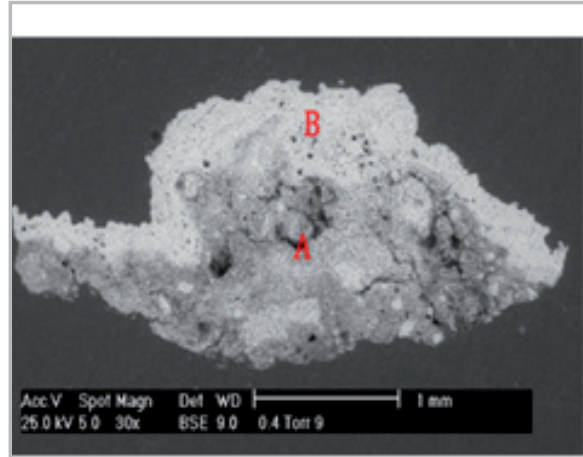

a)

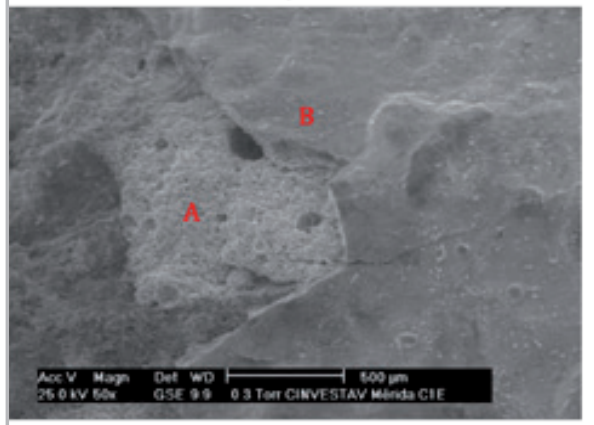

d)

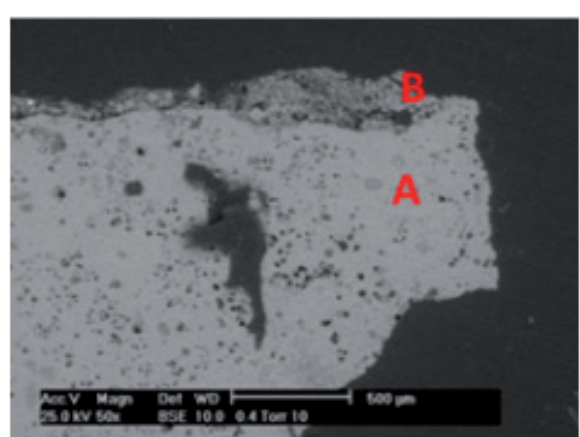

b)

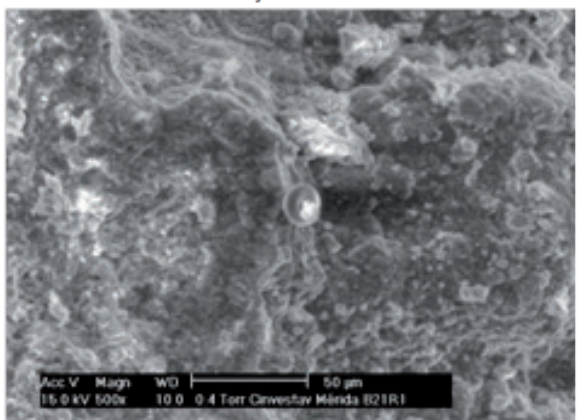

e)

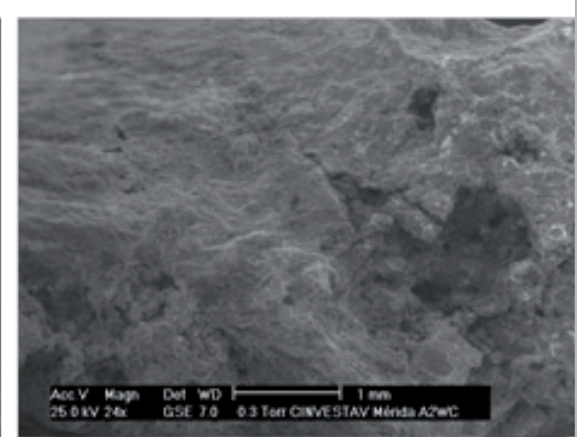

C)

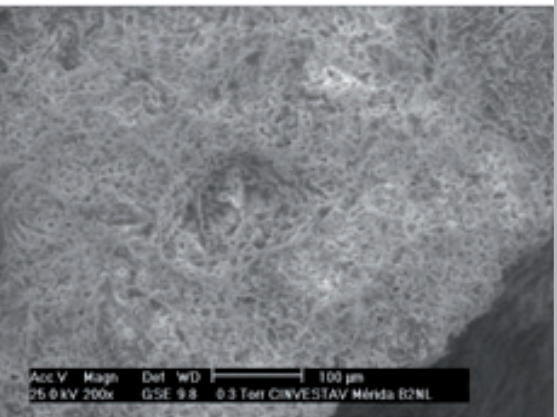

f)

Figura 3.- Imágenes MEB de muestras de BSP y BSC. a) Muestra 3, zona intemperizada (30x) A: sustrato, B: zona intemperizada; b) muestra 4, corte transversal (50x), A: costra cristalizada, B: sustrato; c) muestra 15, superficie intemperizada (24x); d) muestra 2 (50x): A: sustrato, B: costra cristalizada; e) muestra 11, estructuras microbianas (100x), y f) muestra 27, exopolímeros microbianos (200x). 
Tabla 3.- Composición elemental (\% peso) de muestras provenientes del BSC y BSP.

\begin{tabular}{|c|c|c|c|c|c|c|c|c|c|c|c|c|c|c|}
\hline \multirow{2}{*}{ Edificio } & \multirow{2}{*}{ Muro } & \multirow{2}{*}{ Muestra } & \multicolumn{12}{|c|}{ Composición elemental MEB/EDS (\% peso) } \\
\hline & & & & O & $\mathrm{Na}$ & $\mathrm{Mg}$ & $\mathrm{Al}$ & $\mathrm{Si}$ & $\mathrm{P}$ & $\mathrm{S}$ & $\mathrm{Cl}$ & K & $\mathrm{Ca}$ & $\mathrm{Fe}$ \\
\hline \multirow{15}{*}{ BSP } & \multirow{2}{*}{ Oeste } & 1 & 35,39 & 31,72 & * & * & * & * & * & * & 0,92 & * & 32,89 & * \\
\hline & & 2 & 32,72 & 48,48 & 0,31 & 0,090 & 9,87 & 0,44 & * & * & 0,46 & * & 7,50 & 0,14 \\
\hline & \multirow{3}{*}{ Sur-oeste } & 3 & 23,49 & 38,26 & * & 0,78 & 1,13 & 2,24 & * & 0,60 & 0,86 & * & 32,64 & $*$ \\
\hline & & 4 & 46,75 & 30,54 & * & * & 1,12 & 2,86 & 1,59 & 0,44 & * & 0,29 & 16,42 & * \\
\hline & & 5 & 18,09 & 53,93 & * & * & 0,57 & 0,55 & * & 0,30 & * & * & 26,57 & $*$ \\
\hline & \multirow{2}{*}{ Sur } & 6 & 67,94 & 24,24 & 0,45 & * & 0,22 & 0,72 & * & 0,87 & 0,58 & * & 4,99 & $*$ \\
\hline & & 7 & 30,07 & 46,78 & 0,57 & 0,20 & 3,48 & 1,11 & * & 0,98 & 0,72 & * & 15,83 & 0,26 \\
\hline & \multirow{2}{*}{ Este } & 8 & 79,54 & 19,42 & * & * & * & 0,22 & * & * & 0,41 & * & 0,42 & * \\
\hline & & 9 & 36,05 & 57,59 & 0,43 & 0,18 & 1,55 & 0,57 & * & 0,15 & 0,28 & * & 3,17 & 0,08 \\
\hline & Norte & 10 & 76,21 & 23,34 & * & * & 0,27 & * & * & $*$ & 0,11 & $*$ & 0,07 & * \\
\hline & \multirow{5}{*}{ Norte } & 11 & 18,20 & 39,80 & 0,70 & * & 0,70 & 1,30 & 1,30 & 0,30 & 0,30 & $*$ & 37,00 & 0,50 \\
\hline & & 12 & 21,50 & 44,20 & * & 0,70 & 0,80 & 1,70 & 0,30 & 0,60 & $*$ & $*$ & 30,20 & * \\
\hline & & 13 & 16,60 & 42,20 & 1,70 & * & * & 0,50 & * & * & * & 0,90 & 37,90 & $*$ \\
\hline & & 14 & 21,05 & 39,30 & * & * & 0,40 & 1,21 & * & * & * & * & 36,50 & 0,60 \\
\hline & & 15 & 21,90 & 34,90 & 13,90 & 1,10 & 0,40 & 1,60 & * & * & 7,00 & 0,50 & 18,40 & * \\
\hline \multirow{13}{*}{ BSC } & \multirow{7}{*}{ Oeste } & 16 & 43,70 & 28,00 & 0,90 & 0,80 & 0,90 & 1,80 & 0,70 & 3,00 & 0,50 & 0,50 & 18,70 & 0,50 \\
\hline & & 17 & 12,40 & 24,40 & 0,50 & * & 1,20 & 3,80 & * & 2,50 & 1,10 & 1,90 & 50,00 & $*$ \\
\hline & & 18 & 19,10 & 36,30 & * & * & * & 0,40 & * & * & * & 0,70 & 43,30 & $*$ \\
\hline & & 19 & 17,20 & 39,70 & 3,70 & 1,50 & 0,50 & 1,40 & * & 1,20 & * & 1,00 & 33,80 & $*$ \\
\hline & & Sur & 21,20 & 44,90 & 0,90 & 0,60 & 0,10 & 0,40 & * & * & 0,20 & * & 31,30 & $*$ \\
\hline & & 21 & 16,60 & 42,90 & 0,80 & 2,90 & * & 0,80 & * & * & * & * & 35,90 & $*$ \\
\hline & & 22 & 22,80 & 46,90 & * & 0,30 & * & 0,30 & * & * & * & * & 29,50 & $*$ \\
\hline & \multirow{2}{*}{ Sur-oeste } & 23 & 19,00 & 37,00 & 1,10 & * & 0,60 & 1,80 & $*$ & * & * & * & 40,30 & $*$ \\
\hline & & 24 & 29,80 & 38,60 & * & 1,20 & 3,90 & 8,30 & * & * & * & * & 17,90 & $*$ \\
\hline & \multirow{4}{*}{ Este } & 25 & 17,00 & 39,70 & * & 0,30 & 0,40 & 1,00 & 0,50 & 0,30 & * & * & 40,30 & * \\
\hline & & 26 & 14,30 & 34,60 & * & * & 0,70 & 1,60 & * & * & * & * & 47,50 & $*$ \\
\hline & & 27 & 26,70 & 36,00 & * & 0,30 & 0,30 & 0,50 & * & 0,30 & * & * & 35,50 & $*$ \\
\hline & & 28 & 17,50 & 42,20 & * & 0,50 & 0,60 & 1,27 & * & 0,20 & 0,30 & * & 37,10 & * \\
\hline
\end{tabular}

Las micrografías de la figura 3, presentan diferentes aspectos de la alteración en muestras de los muros del BSC y BSP. Sus zonas externas, tienen aspecto quebradizo y textura porosa (figuras $3 \mathrm{a}$-c), espesor variable $(0.3$ a $0,7 \mathrm{~mm}), y$ están sobre un sustrato de aspecto deleznable y porosidad variable (figuras 3 a-d). Se observan estructuras microbianas de forma redondeada y conglomerados de hifas sobre material disgregado (figuras 3 e-f), lo que seguramente es consecuencia de la penetración de talos liquénicos en la matriz pétrea, induciendo fragmentación y pérdida de materiales (Allsopp et al. 2008).

La tabla 4 muestra las fases minerales identificadas mediante FTIR en las muestras de ambos baluartes, algunos espectros representativos se muestran en la figura 4. Estas fases fueron calcita y aragonita $\left(\mathrm{CaCO}_{3}\right)$, cuarzo $\left(\mathrm{SiO}_{2}\right)$ y dolomita $\left(\mathrm{CaMg}\left(\mathrm{CO}_{3}\right)_{2}\right)$, especies asociados a materiales de construcción (García et al. 2006; Reyes et al. 2016). 


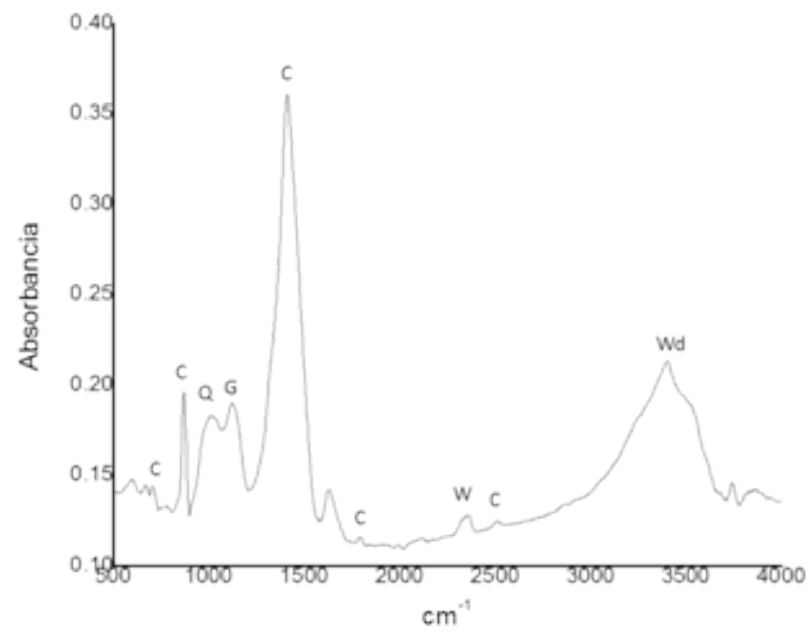

a)

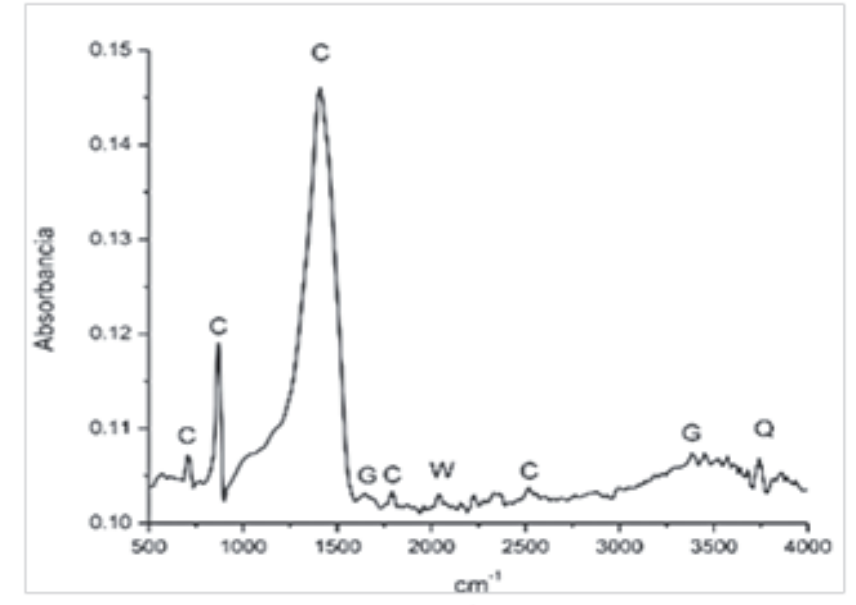

c)

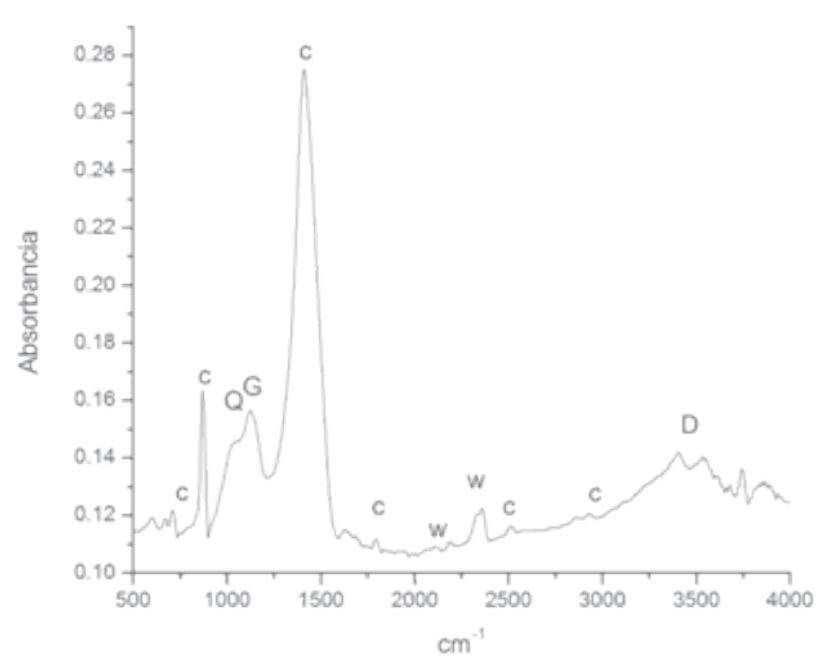

b)

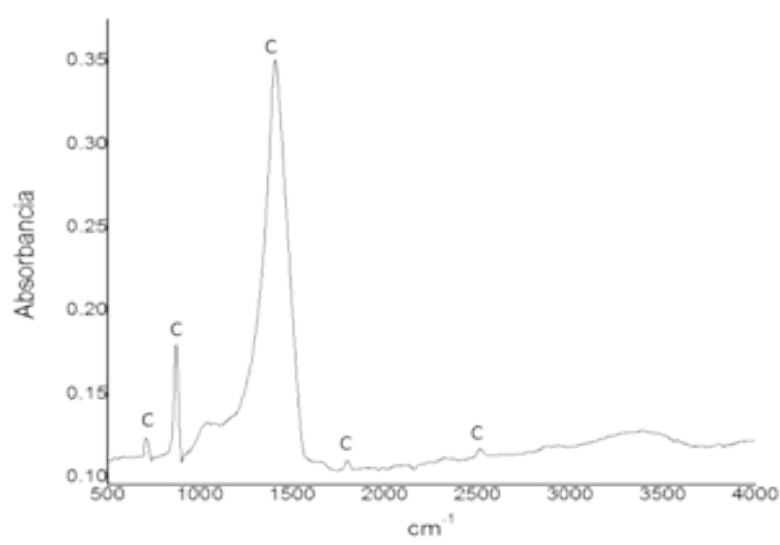

d)

Figura 4.- Espectros FTIR de la superficie de las muestras a) 3 y b) 5 del BSP; c) 20 y d) 25 del BSC. C: calcita, Q: cuarzo, G: yeso, W: wevelita, Wd: wedelita, D: dolomita.

Por su parte, oxalatos de calcio como wevelita $\left(\mathrm{CaC}_{2} \mathrm{O}_{4} \cdot \mathrm{H}_{2} \mathrm{O}\right)$ y wedelita $\left(\mathrm{CaC}_{2} \mathrm{O}_{4} \cdot 2 \mathrm{H}_{2} \mathrm{O}\right)$, así como yeso $\left(\mathrm{CaSO}_{4} \cdot 2 \mathrm{H}_{2} \mathrm{O}\right)$, son neominerales producto de reacciones ambientales, los dos primeros relacionados con la actividad microbiana, mientras que el yeso un producto típico de ambientes contaminados, y componente principal de las costras negras (Pérez- Alonso et al. 2003; Castro y Barbosa 2013).

\section{- Área ocupada por las alteraciones}

El registro fotográfico y análisis de imágenes realizadas en los muros del BSP y BSC, permitió registrar diversas patologías de deterioro que corresponden a pérdida de material (alveolización, fragmentaciones, erosión y microkarst) con valores RGB: 160, 164, 145; alteración cromática y depósitos (biodepósitos, costras negras y eflorescencias) con valores RGB: 79, 86, 90; y colonización microbiana con valores RGB: 33, 37 y 40 [figura 5]. Ejemplo de su distribución respectiva en los muros norte y oeste de BSP y BSC puede apreciarse en la figura 6.

Por su parte, la figura 7 muestra el área ocupada por estos indicadores en los muros de ambos edificios. Se puede apreciar, que la alteración cromática y depósitos constituyen el principal indicador de alteración tanto en el BSC como en el BSP, ocupando el 60 y $77 \%$ del área total de sus muros respectivamente. En el BSC, es seguido por pérdida de material (23\%) y colonización microbiana con (16\%) de área total ocupada. Por su parte, en el BSP le siguen colonización microbiana y pérdida de material ocupando el 10 y $12 \%$ de área total respectivamente. 
Tabla 4.- Fases minerales identificadas (*) mediante FTIR/ATR en muestras provenientes de BSP y BSC.

\begin{tabular}{|c|c|c|c|c|c|c|c|c|c|}
\hline \multirow[b]{2}{*}{ Edificio } & \multirow[b]{2}{*}{ Muro } & \multirow[b]{2}{*}{ Muestra } & \multicolumn{7}{|c|}{ Fases minerales $\mathrm{v}, \mathrm{cm}^{-1}$} \\
\hline & & & $\begin{array}{c}\text { Aragonita } \\
1.079\end{array}$ & $\begin{array}{c}\text { Calcita } \\
710 \\
2.951\end{array}$ & $\begin{array}{c}\text { Cuarzo } \\
1.050 \\
1.645\end{array}$ & $\begin{array}{c}\text { Dolomita } \\
3.536\end{array}$ & $\begin{array}{c}\text { Wevelita } \\
2.013 \\
2.356\end{array}$ & $\begin{array}{c}\text { Wedelita } \\
3.409\end{array}$ & $\begin{array}{c}\text { Yeso } \\
671 \\
1.125\end{array}$ \\
\hline \multirow{15}{*}{ BSP } & \multirow{2}{*}{ Oeste } & 1 & * & + & + & * & * & + & * \\
\hline & & 2 & * & + & + & * & * & + & * \\
\hline & \multirow{3}{*}{ Sur-oeste } & 3 & * & + & + & * & + & + & + \\
\hline & & 4 & * & + & + & * & + & + & + \\
\hline & & 5 & * & + & + & + & + & * & + \\
\hline & \multirow{2}{*}{ Sur } & 6 & + & + & + & * & + & * & * \\
\hline & & 7 & * & + & + & * & + & + & + \\
\hline & \multirow{2}{*}{ Este } & 8 & * & + & + & * & * & + & + \\
\hline & & 9 & * & + & + & * & + & + & + \\
\hline & Norte & 10 & * & + & * & * & + & * & + \\
\hline & \multirow{5}{*}{ Norte } & 11 & * & + & * & * & * & * & * \\
\hline & & 12 & * & + & * & * & * & * & * \\
\hline & & 13 & * & + & * & * & * & * & * \\
\hline & & 14 & * & + & * & * & * & * & * \\
\hline & & 15 & $*$ & + & + & * & * & * & * \\
\hline \multirow{13}{*}{ BSC } & \multirow{7}{*}{ Oeste } & 16 & * & + & * & * & * & + & * \\
\hline & & 17 & $*$ & + & $*$ & * & * & * & * \\
\hline & & 18 & * & + & * & * & * & * & * \\
\hline & & 19 & * & + & + & * & * & * & * \\
\hline & & Sur & * & + & + & * & + & * & + \\
\hline & & 21 & * & + & $*$ & * & * & * & $*$ \\
\hline & & 22 & * & + & + & * & * & * & * \\
\hline & \multirow{2}{*}{ Sur-oeste } & 23 & * & + & + & * & * & * & * \\
\hline & & 24 & * & + & + & $*$ & $*$ & $*$ & * \\
\hline & \multirow{4}{*}{ Este } & 25 & * & + & $*$ & * & * & $*$ & $*$ \\
\hline & & 26 & * & + & * & * & * & * & * \\
\hline & & 27 & * & + & + & $*$ & * & * & * \\
\hline & & 28 & * & + & + & * & * & * & * \\
\hline
\end{tabular}

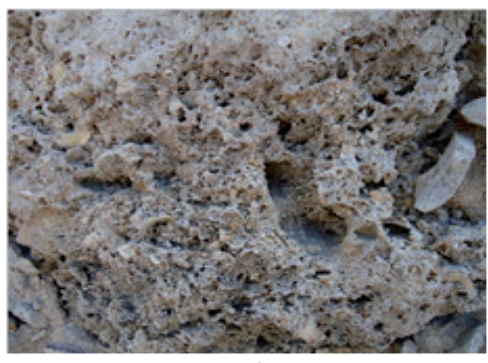

a)

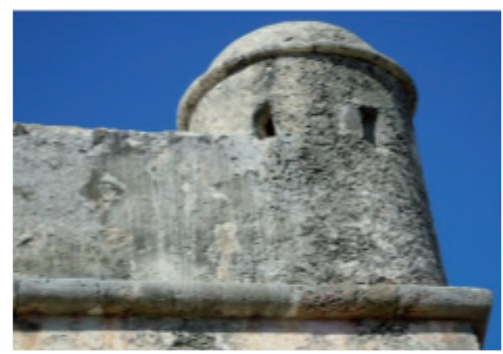

d)

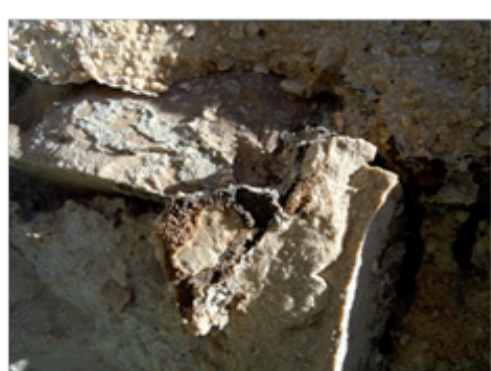

b)

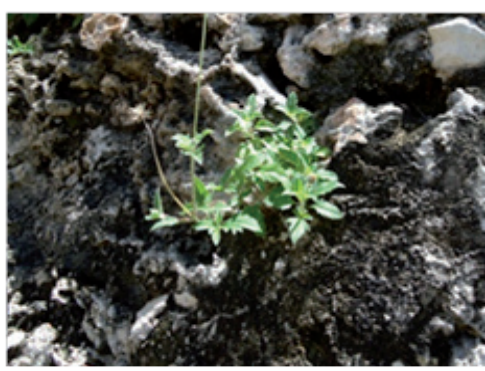

e)

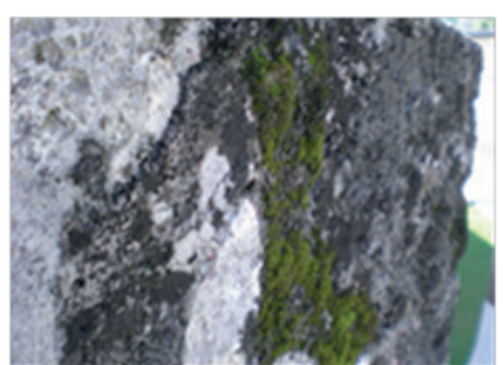

c)

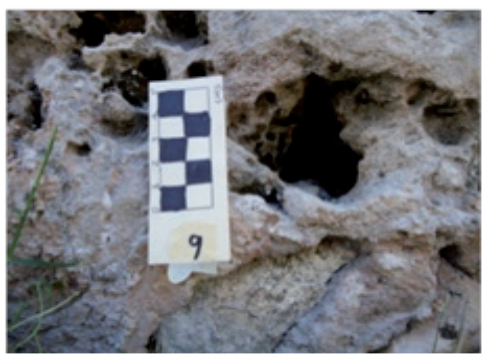

f)

Figura 5.- Espectros FTIR de la superficie de las muestras a) 3 y b) 5 del BSP; c) 20 y d) 25 del BSC. C: calcita, Q: cuarzo, G: yeso, W: wevelita, Wd: wedelita, D: dolomita. 

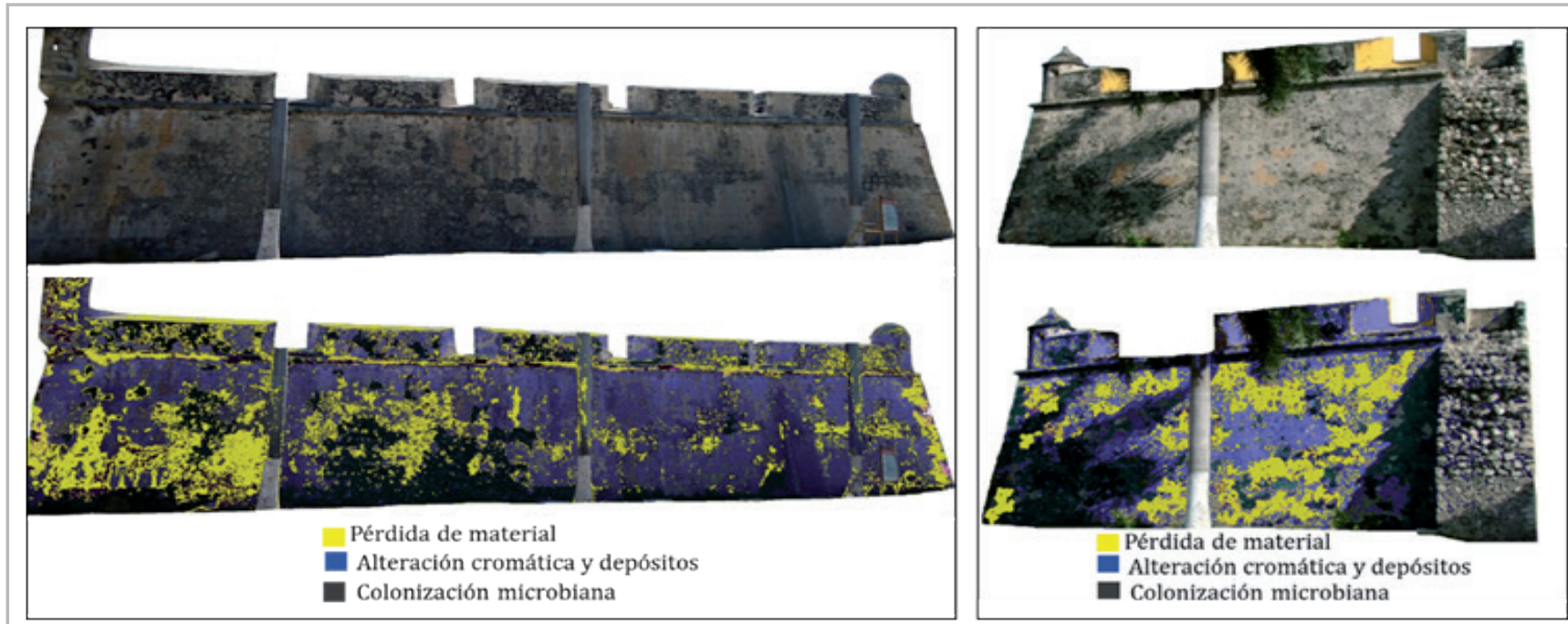

Figura 6.- Indicadores de alteración presentes en los muros a) oeste del BSC y b) norte del BSP.

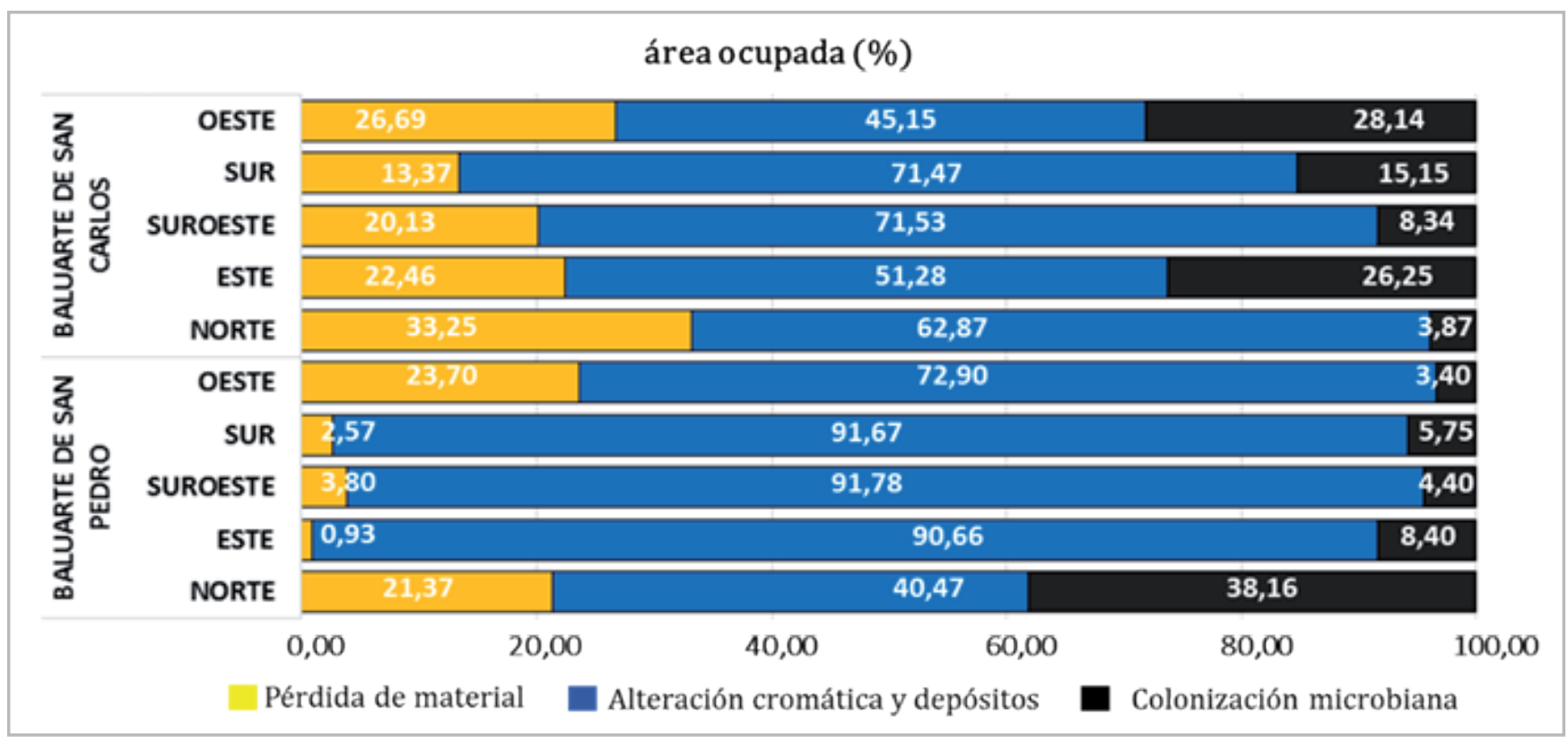

Figura 7.- Gráfico de acumulación de indicadores de alteración observados en los muros de BSC y BSP.

-Asignación de los estadios de alteración de acuerdo con el sistema UAS

De acuerdo con los resultados de la caracterización química, se estableció un nivel de certeza C2 para todos los muros del BSC y BSP, mientras que los indicadores de deterioro y el área que ocupan en los muros, definió el estadio de alteración correspondiente [tabla 5].

Para los muros este, sur, suroeste y oeste del BSP [figura 7], la evaluación visual identificó principalmente alteraciones cromáticas y pérdida de material. En sus vértices se observaron rupturas superficiales (U1), mientras que en las intersecciones de zonas centrales se observó pérdida de materiales (A1), lo que correspondió a áreas específicas de la fachada (SO). De acuerdo con el sistema UAS, estas características correspondieron a una clasificación Estadio 2 (A1U1S0). En el caso del muro norte la pérdida de material se estimó mayor al $10 \%$ del área superficial (A2), abarcando bloques individuales completos (U2), condición que corresponde a un estadio de deterioro 3 (A2U2SO) [figura 8]. Cabe mencionar que en este muro también se evidenció un alto porcentaje de colonización microbiana (38,16\% de la superficie). Es bien sabido que el desarrollo microbiano sensibiliza los sustratos pétreos, favoreciendo su alteración y posterior disgregación (Ramírez 2012).

En el BSC, el muro este presenta pérdida de material que afecta a partes de bloques individuales y bloques adyacentes limitado a secciones dispersas del muro, 
Tabla 5.- Estadio de alteración en los muros de BSC y BSP, de acuerdo con el sistema de estadificación UAS.

\begin{tabular}{|c|c|c|c|}
\hline Edificio & Muro & Clasificación & Estadio de alteración \\
\hline \multirow{4}{*}{ BSP } & Sur & U1-A1-S0 & 2 \\
\cline { 2 - 4 } & Suroeste & U1-A1-S0 & 2 \\
\cline { 2 - 4 } & Este & U1-A1-S0 & 2 \\
\cline { 2 - 4 } & Oeste & U1-A1-S0 & 2 \\
\cline { 2 - 4 } & Norte & U2-A2-S0 & 3 \\
\hline \multirow{7}{*}{ BSC } & Sur & U1-A1-S0 & 2 \\
\cline { 2 - 4 } & Suroeste & U1-A1-S0 & 2 \\
\cline { 2 - 4 } & Este & U1-A1-S0 & 2 \\
\cline { 2 - 4 } & Oeste & U3-A2-S0 & 4 \\
\cline { 2 - 4 } & Norte & U3-A2-S0 & 4 \\
\hline
\end{tabular}

correspondiéndoles un estadio de deterioro 2 (U1A1S0) [figura 8]. Esto ocurrió también con los muros sur y suroeste. En estos muros, las alteraciones se deben principalmente a procesos de alveolización y karstificación. El estadio de alteración señala la necesidad de realizar medidas correctivas específicas, con alcance de la intervención limitada a pérdida de material en los límites de los bloques imaginarios trazados para seccionar los muros, para lo cual resulta necesaria la consolidación de las zonas afectadas por alveolizaciones. Por el contrario, los muros norte y oeste directamente expuestos a emisiones vehiculares mostraron pérdida generalizada de bloques completos, con $20 \%$ de área total de la fachada ocupada, lo que implica un estadio 4 (U3A3S0), el más alto dentro de la clasificación de Warke. Esto implica intervenciones mayores para restaurar el muro, considerando acciones necesarias para la protección del edificio.

\section{Conclusiones}

El sistema de estadificación UAS permitió establecer los estadios de alteración de los muros de los Baluartes de San Carlos (BSC) y San Pedro (BSP) de la Ciudad de San Francisco de Campeche (SFC), México, a partir de la cuantificación de áreas de deterioro calculadas mediante análisis de imágenes. Durante el estudio, se establecieron niveles de certeza basados en la caracterización elemental y mineral de indicadores de alteración empleando MEB/ EDS y FTIR, lo que fortalece la clasificación obtenida mediante el sistema UAS, y facilita la toma de decisiones para el establecimiento de futuros paliativos a los procesos de deterioro que afectan los muros de ambos edificios.

La clasificación UAS señala que el mayor estadio de alteración se presenta en los muros norte y oeste de BSC con categoría 4, y norte en BSP con categoría 3. Todos los demás muros en ambos edificios presentan estadio 2 .

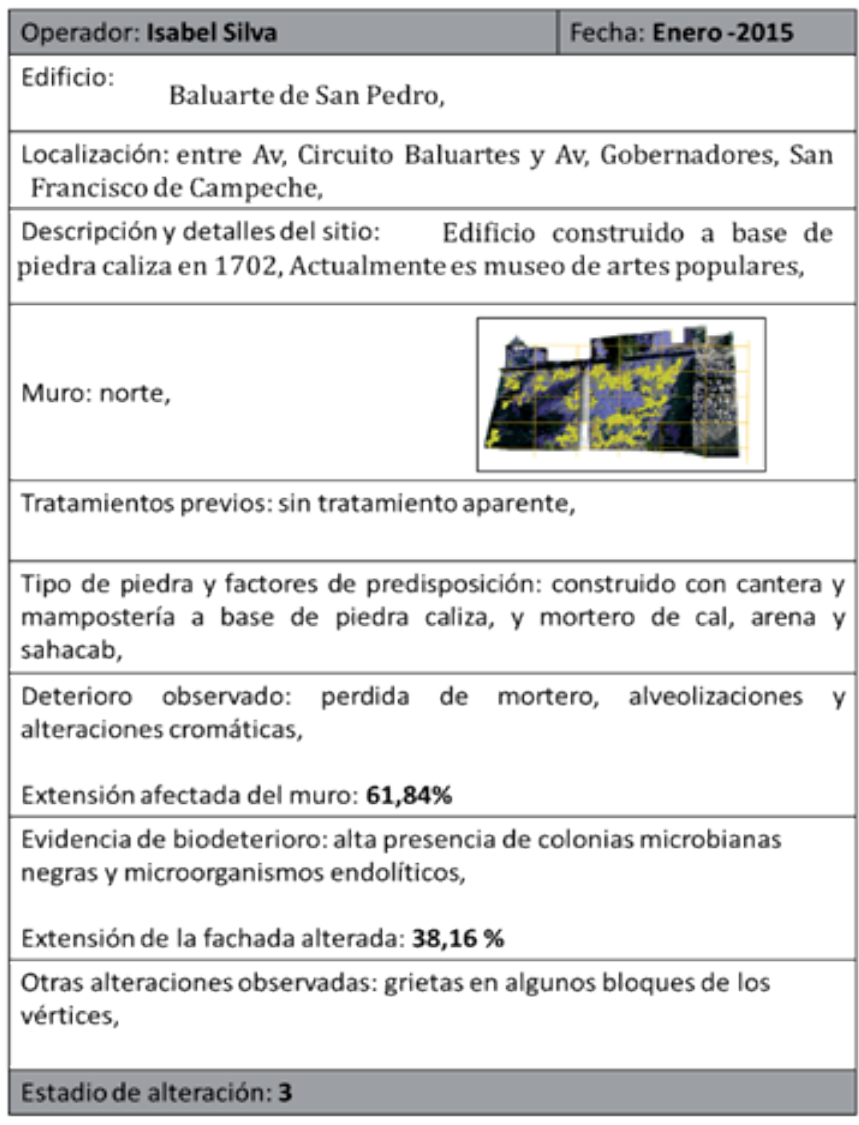

\section{Operador: Isabel Silva}

Fecha: Enero-2015

Edificio:

\section{Baluarte de San Carlo,s}

Localización: entre Av, Circuito Baluartes y Calle 8,

Descripción y detalles del sitio: Edificio construido a base de piedra caliza en 1680, Actualmente resguarda el museo de la ciudad,

Muro: Este,

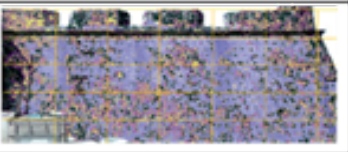

Tratamientos previos: morteros recientes,

Tipo de piedra y factores de predisposición: muros de mampostería de roca calcárea, sahacab y piedras de cantera,

Deterioro observado: perdida de mortero, costras de deterioro, eflorescencias, alveolizaciones,

Extensión afectada del muro: $\mathbf{7 3 , 5 \%}$

Evidencia de biodeterioro: presencia de colonias microbianas negras,

Extensión de la fachada alterada: $\mathbf{2 6 , 5} \%$

Otras alteraciones observadas: grietas en algunos bloques de los vértices, asi como microkarst en piedra desnuda,

Estadio de alteración: 3

Figura 8.- Hojas de registro representativas del sistema de estadificación UAS para los muros norte y este de BSP y BSC respectivamente. 
Esta diferencia es consecuencia de procesos de alteración preferencial que dependen de las características del sustrato pétreo, la orientación del muro y de la calidad ambiental del entorno que rodea el edificio. En este sentido, los indicadores de alteración observados en ambos edificios fueron: alteración cromática y depósitos, pérdida de material y colonización microbiana.

Cabe mencionar que los estadios de alteración obtenidos, corresponden a los existentes en el momento de realizar las mediciones, por lo que en un entorno urbano siempre cambiante como el prevaleciente en SFC, la clasificación obtenida puede modificarse a lo largo del tiempo, por lo es pertinente realizar evaluaciones periódicas con el fin de establecer patrones de alteración, y comprobar la eficacia de acciones de conservación que deben ser aplicados en los muros del BSC y BSP, entre los cuales se deben considerar: trabajos de limpieza, remoción de depósitos, tratamientos consolidantes y antimicrobianos, reposición de morteros en zonas específicas y renovación de bloques. En todas estas acciones se debe garantizar mantener el aspecto original del edificio y evitar daños internos en los materiales.

\section{Agradecimientos}

Los autores agradecen el apoyo prestado por el Proyecto CONACYT LANCIC LN314846 y al Centro INAH Campeche, para la realización de esta investigación. Así mismo, al Dr. Juan Illescas Salinas, por enriquecer este trabajo con sus observaciones.

\section{Referencias}

ALONZO, L.Y ESPINOZA, L. (2003). “Estudio de las propiedades de la roca caliza de Yucatán". Ingeniería, 7(1): 27-3.6.

ALLSOPP, D., SEAL, K. Y GAYLARDE, C. (2008). Introducción al Biodeterioro. Zaragoza: Editorial Acribia, S.A.

ARNOLD, A., JEANNETTE D. Y ZEHNDER K. (1980). “Proposal for a terminology of weathering phenomena on building stones", Centre Documentation ICOMOS. 1-26

ARROYO, I. (2009). "Aproximación al problema de las aves sobre monumentos efectos colaterales", en: La incidencia de las aves en la conservación de monumentos. Instituto de Patrimonio de Cultura de España, 9- 20.

ASO P.J. Y BUSTOS N. V. (1991). “Uso de residuos orgánicos, estiércol y cachaza, como abonos", Avance Agroindustrial, 44: 2325.

BONAZZA, A., SABBIONI C. Y GHEDINI, N. (2005). "Quantitative data on carbon fractions in interpretation of black crusts and soiling on European built heritage", Atmospheric Environment, 39(14): 2607-2618. https://doi.org/10.1016/j. atmosenv.2005.01.040
BOSCH, I., GOSALBEZ, J., SALAZAR, A., VERGARA, L., Y MIRALLES, R. (2005). "Análisis ultrasónico en aplicaciones de restauración arquitectónica". https://www.researchgate.net/profile/lgnacioBosch/publication/239932428 ANALISIS ULTRASONICO EN APLICACIONES DE RESTAURACION ARQUITECTONICA/ links/58b961a4aca27261e51cf1ad/ANALISIS-ULTRASONICO-ENAPLICACIONES-DE-RESTAURACION-ARQUITECTONICA.pdf

BRAVO, A. H., SOTO, R.., SOSA, R. Y SANCHEZ, P. (2003) “Efecto de la Iluvia acida en el material constituyente de monumentos mayas mexicanos", Ingeniería Investigación y tecnología. 4: 195-205. https://doi.org/10.22201/fi.25940732e.2003.04n4.016

CASTRO, T. Y BARBOSA. (2013). “Enfoque químico del deterioro y biodeterioro de rocas calcáreas conformantes de monumentos patrimoniales de importancia histórica y cultural", Revista Luna Azul, 36: 247-284. https://doi.org/10.17151/luaz.2013.36.13

CLARKE, R. M. Y WILLIAMS I. R. (1986). "Moolooite, a naturally occurring hydrated copper oxalate from Western Australian", Mineralogical Magazine, 295-298. https://doi.org/10.1180/ minmag.1986.050.356.15

ESCAMILLA, R., REYES, J., PÉREZ, T., MONTEÓN, V. Y LÓPEZ, R. (2012). "Identification of Microorganisms Associated to the Biodegradation of Historic Masonry Structure in San Francisco de Campeche City, México". Mat. Reseacrh Society Symposium Proceedins. Material Research Society. https://doi.org/10.1557/ opl.2012.1388.

ESPINOSA-MORALES, Y., ALARCÓN, A. L., DOMÍNGUEZ-CARRASCO, M., MARTÍNEZ- MIRANDA, V., ARTEAGA- ARCOS, J. C., SILVA- LEÓN, I. Y REYES, J. (2020). "An Approach to Identify and Understand the Main Processes of Weathering that Suffer the Pre-Hispanic Stelae Located in the CALAKMUL Biosphere Reserve in Campeche, Mexico". Archaeometry. 1-17 https://doi.org/10.1111/arcm.12640

GAINZA- LUZEA, M. (2015). El deterioro de la piedra en el patrimonio construido y aplicación de nanoformulaciones para la conservación de los mismos. Tesina del máster de arquitectura, energía y medio ambiente. Universidad Politécnica de Cataluña.

GALÁN, E., GUERRERO, M. A., VÁZQUEZ, M. A., CARRETERO, M. I. Y ORTIZ, P. (1996). "The cathedral of Cadiz (Spain): environmental study and stone damage evaluation", en Proceedings of European Commission Research Workshop on Origin, Mechanisms and Effects of Salts on Degradation in Marine and Continental Environments, 61-62.

GARCÍA - MURILLO, S. Y MARTÍN- PÉREZ, A. (2006). “Los organismos vivos como factores que contribuyen activamente al deterioro de nuestros monumentos", Boletín del Instituto Andaluz de Patrimonio Histórico, 14(57): 57-66. https://doi.org/10.33349/1996.14.297

GARCÍA-SOLÍS, C., QUINTANA, P. Y BAUTISTA, F. (2006). "La identificación de materiales arcillosos y pétreos utilizados en la manufactura del friso modelado en estuco de la SUBII-C1 de Calakmul, a través del análisis de difracción de rayos $\mathrm{X}^{\prime \prime}$, La ciencia de materiales y su impacto en la arqueología, 2: 237-252. 
GÓMEZ-HERAS, M. (2012). "La temperatura en los materiales del Patrimonio", en La conservación de los geomateriales utilizados en el patrimonio, Madrid, 87- 96

GÓMEZ-HERAS, M., GARCIA MORALES, S. Y FORT, R. (2013). "Integración de datos de termografía de infrarrojos y otras técnicas no destructivas en detección de humedades y sales", Jornada de Técnicas de Reparación y Conservación del Patrimonio, 11.

GÓMEZ-HERAS, M., MCALLISTER, D., FLECHOSO, M. D. L. A. G., FORT, R. Y MORALES, S. G. (2014).“Ejemplos de análisis cuantitativo de imágenes de infrarrojos obtenidas por termografía activa para la detección de patologías de humedades". En Congreso Latinoamericano sobre patología de la construcción, tecnología de la rehabilitación y gestión del patrimonio: REHABEND 2014, Santander (España), 461-468.

GÓMEZ LÓPEZ, M. J. (2016). Uso de la radiografía digital en la valoración de antiguas intervenciones en cerámica arqueológica. Trabajo final de master universitario en conservación y restauración de bienes culturales. Universidad Politécnica de Valencia. http://hdl.handle.net/10251/64391

GONZÁLEZ, M. J. G. Y RAMÍREZ, N. L. R. (2015). “La rehabilitación urbana sostenible en centros históricos: los casos de León (España) y Puebla (México)", Estudios Geográficos, 76(279): 531-555. https:// doi.org/10.3989/estgeogr.201519

GUTIÉRREZ-TORRES, G. I. (2008). Caracterización de costras de deterioro del Baluarte de San Carlos del Conjunto HistóricoArquitectónico de San Francisco de Campeche, mediante técnicas analíticas avanzadas. Tesis de Licenciatura. Facultad de Ciencias Químico Biológicas, Universidad Autónoma de Campeche, México.

HUITZ- BAQUEIRO, C.M. (2005). "Fortificación de San Francisco de Campeche. Arquitectura, usos, arqueología y restauración", Diario de campo. Boletín interno de los investigadores del área de antropología. 22-25.

ICOMOS-ISCS glosario en línea. (2008). http://Irmh-ext.fr/icomos/ consult/index.htm. [Consulta: 10/02/2014].

INSTITUTO ANDALUZ DEL PATRIMONIO HISTÓRICO (IAPH). (2018). Patrimonio de piedra guía didáctica. https://colaboraeducacion 30 . juntadeandalucia.es/educacion/colabora/web/vivir-y-sentirel-patrimonio/redessociales/-/blogs/patrimonio-en-piedrageologia-y-conservacion. [Consulta: 01/08/2018]

INSTITUTO NACIONAL DE ESTADÍSTICA Y GEOGRAFÍA (INEGI) (2019). https://www.inegi.org.mx/temas/vehiculos/default. html\#Tabulados. [Consulta: 05/01/2019]

JURADO, V., MILLER, A. Z., CUEVA, S., FERNÁNDEZ-CORTES, A., BENAVENTE, D., ROGERIO-CANDELERA, M. A. Y SAIZ-JIMÉNEZ, C. (2014). "Recolonization of mortars by endolithic organisms on the walls of San Roque church in Campeche (Mexico): A case of tertiary bioreceptivity", Construction and Building Materials, 53: 348-359. https://doi.org/10.1016/j.conbuildmat.2013.11.114
MARTíN, L. (1992). Diagnóstico sobre el estado de alteración de los materiales pétreos de la Catedral de Granada. Tesis Doctoral. Universidad de Sevilla.

ORDAZ TAMAYO, M. Y BOJÓRQUEZ CARVAJAL, I. (2015). “La bóveda de rollizos de las iglesias coloniales de Yucatán". En Actas del Noveno Congreso Nacional y Primer Congreso Internacional Hispanoamericano de Historia de la Construcción: 3: 1249-1258. Segovia.

ORTIZ, R., ORTIZ, P., ABAD, M. Y MARTíN, J. (2012). “Estudio estratigráfico de costras y depósitos en templos del casco histórico de Sevilla", Revista ph, (83). https://doi.org/10.33349/2012.83.3343

PÉREZ- ALONSO, L., CASTRO, K., RODRIGUEZ-LASO, M. ${ }^{a}$ D. Y MADARIAGA, J.M. (2003).“Desarrollo de un nuevo tratamiento para la conservación de piedras con alto contenido en carbonatos utilizando la Tecnología de Resinas de Intercambio lónico", Arqueología de la arquitectura, 2: 235-239. https://doi.org/10.3989/arq.arqt.2003.52

RAMÍREZ VÁZQUEZ, M. (2012). Biodeterioro algal en monumentos históricos mayas de la zona tropical húmeda: Palenque, Yaxchilán y Bonampak (Chiapas, México). Tesis doctoral. Universidad de Barcelona. http://hdl.handle.net/2445/42694.

REYES, J., CORVO F., ESPINOSA-MORALES, Y., DZUL, B., PÉREZ, T., AGUILAR, D. Y QUINTANA, P. (2011). "Influence of Air Pollution on Degradation of Historic Buildings at the Urban Tropical Atmosphere of San Francisco de Campeche City, México", en Monitoring, Control and Effects of Air Pollution, 201-226. https://doi.org/10.5772/18739

REYES, J., SILVA, I., PÉREZ, T., CORVO, F., MARTíNEZ, W., ALONSO, E. M. Y QUINTANA, P. (2012). “El deterioro del baluarte de san pedro, un estudio de caso", Revista ALCONPAT, 2(3): 170-184. https://doi. org/10.21041/ra.v2i3.35

REYES TRUJEQUE, J., COBO RIVERA, J. M., QUINTANA OWEN, P., BARTOLO- PÉREZ, P., PÉREZ LÓPEZ, T., CASANOVA GONZÁLEZ, E. Y CORVO- PÉREZ F. (2016). "Weathering effects of an historic building in San Francisco de Campeche, Mexico", Intervención: Revista de Conservación, Restauración y Museología, 13: 22-31. https://www. redalyc.org/articulo.oa?id=355644889003

ROGERIO-CANDELERA, M. A. (2010). "El análisis de imagen como herramienta de investigación no invasiva de cuevas con arte rupestre". En Cuevas: Patrimonio, Naturaleza. Madrid: Asociación de Cuevas Turísticas Españolas, Cultura y Turismo, 203-216.

ROMÁN- KALISCH, M. A. (2010). “La edificación de los conjuntos parroquiales en el Yucatán virreinal". Boletín de monumentos históricos, 20: 70-97.

RUBIERA, N. P. (2014). “El tratamiento digital de imágenes como una herramienta de evaluación y análisis en la restauración y conservación del patrimonio arquitectónico", Revista Electrónica ReCoPar, 1: 41-53.

SMN. (2020). Estaciones Meteorológicas Automáticas (EMAS). https://smn.conagua.gob.mx/es/observando-el-tiempo/estaciones-meteorologicas-automaticas-ema-s. [Consulta: 01/06/2020]. 
STELFOX, D. "Natural Stone Database. Online information for the stone-built heritage of Northern Ireland". http://www. stonedatabase.com/. [consulta: 27/03/21].

THORNBUSH, M. Y VILES, H. (2006). "Changing patterns of soiling and microbial growth on building stone in Oxford, England after implementation of a major traffic scheme", Science of the Total Environment, 367(1): 203-211. https://doi.org/10.1016/j. scitotenv.2005.11.022

TORRES- GONZÁLEZ, F.A. (2009). Efecto de la lluvia en materiales pétreos del patrimonio histórico del Estado de Campeche. Tesis de Maestría. Facultad de Ingeniería. Universidad Autónoma de Campeche. México.

TORRES LÓPEZ, Á. (2017). Evaluación en el transporte de cloruros en hormigón. Tesis de licenciatura. Universidad Politécnica de Cartagena. http://hdl.handle.net/10317/8407

WARKE, P. A., CURRAN, J. M., TURKINGTON, A. V.Y SMITH, B. J. (2003). "Condition assessment for building stone conservation: a staging system approach", Building and Environment, 38(9): 1113-1123. https://doi.org/10.1016/S0360-1323(03)00085-4

\section{Autor/es}

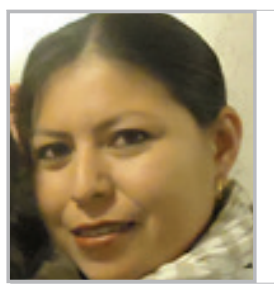

\section{Isabel Silva León}

isssilva@uacam.mx

Centro de Investigaciones en Corrosión. Universidad Autónoma de Campeche

Licenciada en Ingeniería Bioquímica Ambiental y Maestra en Ciencias de la Preservación de Materiales, títulos obtenidos en la Universidad Autónoma de Campeche, México. Se desempeña como técnico docente en el Centro de Investigaciones en Corrosión, como responsable del laboratorio de Difracción de Rayos $\mathrm{X}$, además contribuye con servicios de análisis de diversos materiales: metales, piedras, cerámicas, gemas, entre otros. Apoyo técnico con el uso y aplicación de técnicas espectroscópicas tales como, espectroscopía de infrarrojo por transformada de Fourier y espectroscopía Raman. Ha participado en congresos nacionales e internacionales, como ponente y como colaboradora en diferentes trabajos de investigación. A la vez participa como colaborador en proyectos como: Laboratorio Nacional de Ciencias Para la Investigación y Conservación del Patrimonio Cultural (LANCIC), Programa de Laboratorios Nacionales CONACyT, Red de Ciencias aplicadas a la Investigación y Conservación de Patrimonio Cultural (RED CAICPC-CONACYT), Caracterización y análisis estilístico de las figurillas de Calakmul, Campeche, Estudio integral de deterioro de estelas prehispánicas del sitio arqueológico de Oxpemul, Campeche, Caracterización petrográfica de rocas utilizadas en patrimonio de la península de Yucatán y la Red de Estudios Interdisciplinarios sobre Medio Ambiente y Conservación del Patrimonio Mexicano.

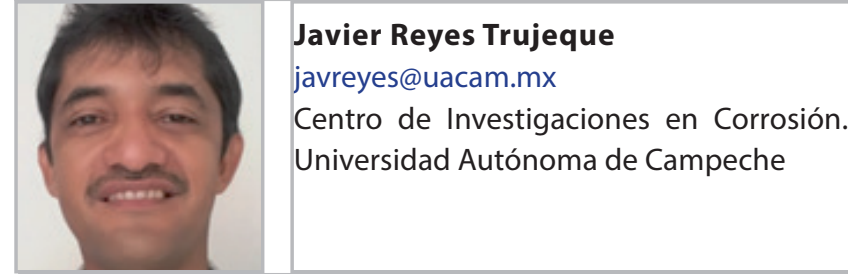

El Dr. Javier Reyes Trujeque es Profesor e Investigador Titular en la Universidad Autónoma de Campeche. En 2004, obtuvo su Doctorado en Ciencias Químicas por la Universidad de Sevilla desarrollando su tesis en el Proyecto CARAMEl, financiado por la Comisión Europea. Desde 2008, es responsable del Grupo de Investigación Ciencia e Ingeniería Ambiental Aplicada al Estudio de Materiales de Interés Histórico y Artístico en el Centro de Investigación en Corrosión al cual se encuentra adscrito. Es especialista en el estudio del comportamiento de materiales en el medio ambiente, con énfasis en la protección del patrimonio histórico y en el empleo de métodos de evaluación no destructivo para el diagnóstico de bienes patrimoniales. Su labor académica lo ha llevado a ser responsable del Posgrado en Ciencias de la Preservación de Materiales, que es financiado por el Consejo Nacional de Ciencia y Tecnología de México, del cual ha sido reconocido como investigador Nacional Nivel 1. Se ha involucrado activamente en la formación de especialistas en la conservación de materiales del Patrimonio Cultural Tangible, por medio de cuya actividad ha actuado como supervisor de numerosas tesis de Licenciatura y Posgrado. El Dr. Reyes ha sido responsable de proyectos de investigación y colaborador en redes académicas y de investigación con instituciones nacionales, latinoamericanas y europeas. Actualmente es el responsable del Nodo Regional del Laboratorio Nacional del Ciencias Para la investigación y Conservación del Patrimonio Cultural, y responsable de la Red de Estudios Interdisciplinarios Sobre Medio Ambiente y Conservación del Patrimonio Mexicano.
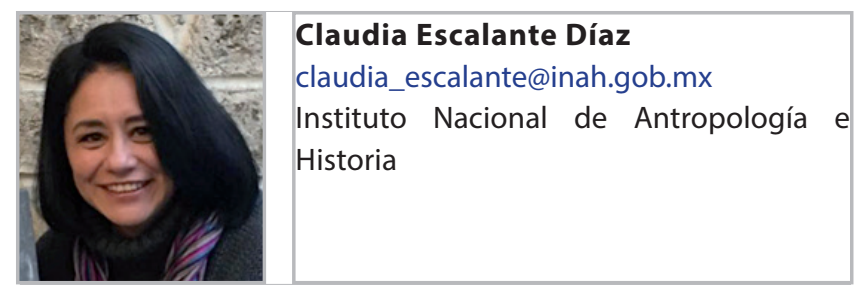

Claudia Elena Escalante Díaz, nacida en la ciudad de San Francisco de Campeche, México. Es Arquitecta de profesión, Maestra en arquitectura con especialidad en restauración de monumentos de la Escuela Nacional de Conservación y Museografía Manuel del Castillo Negrete del INAH, con experiencia de más de dos décadas en restauración arquitectónica, se ha especializados en los últimos años en el trabajo de museos con una visión de accesibilidad universal transformando los museos a su cargo en espacios para todos. Ha incursionado en el campo de la docencia en temas de restauración y conservación del patrimonio cultural tangible y como Directora de la Escuela de Artes Visuales del Instituto Campechano, en Campeche. Ha elaborado y participado en el desarrollo de estudios de mejoramiento de la imagen urbana y en el desarrollo y análisis de temas de imagen urbana en áreas patrimoniales para el Programa Director Urbano para la ciudad de Campeche y en propuestas de restauración 
arquitectónica, urbana y arqueológica en Campeche, Oaxaca, Tamaulipas, Estado de méxico y Ciudad de México. Se desempeñó como directora de Patrimonio de la Unidad De Programas y Proyectos de Inversión Pública del Gobierno del Estado de Campeche, y como Director Adjunto de Obra en Coordinación Estatal de Sitios y Monumentos del Estado de Campeche. Ha dictado conferencias sobre Reestructuraciones integrales en museos, Transmedia en museos, Trabajo comunitario: la cultura para vivirla, Museos en edificios patrimoniales: fortalezas y debilidades, Puntos de encuentro entre la educación formal y la educación no formal, y sobre Accesibilidad universal en museos. Actualmente, es directora de Museos del Centro INAHCampeche.

Artículo enviado el 06/11/2020 Artículo aceptado el 21/04/2021

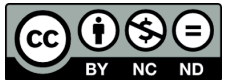

https://doi.org/10.37558/gec.v19i1.861 